\title{
Comparative Study on Changes in Spirometric Lung Function Indices of Cobblestone Workers
}

\author{
Hailemariam H. Mamo \\ Department of Biological Sciences, Dire Dawa University, Dire Dawa, Ethiopia \\ Email address: \\ hailemariammamo5@gmail.com \\ To cite this article: \\ Hailemariam H. Mamo. Comparative Study on Changes in Spirometric Lung Function Indices of Cobblestone Workers. Science Journal of \\ Public Health. Vol. 5, No. 2, 2017, pp. 98-102. doi: 10.11648/j.sjph.20170502.16
}

Received: December 1, 2016; Accepted: December 10, 2016; Published: February 17, 2017

\begin{abstract}
Cobblestone workers exposed to dust inhalation and physical injuries during cobblestone work activities exposed to respiratory problems due to proliferation and fibrotic alteration changing in their spiro metric lung function indices. This study was designed to determine changes in spirometric lung function indices of cobblestone workers. Comparative crosssectional study was applied. Cobblestone workers exposed for one and above years and proportional non exposed non-smoking normal study participants with similar age range and anthropometric values were participated. The study showed higher change in Spiro metric lung function indices. Mean values and percent predicted mean values of lung functions (FVC, FEV1, FEV1/FVC, PEFR, PIFR and FEF25-75) were significantly reduced $(p<0.05)$. Reduction in spirometric values was more marked in chiseling workers. Thus, dust emission during cobblestone preparation adversely affects pulmonary function of workers. Further studies should be conducted on many workers to make standing decisions and regulations. Workers should be trained and appropriate PPEs should be provided. Guideline has to be developed to provide guidance on how to assess and reduce health impacts of dust emissions.
\end{abstract}

Keywords: Cobblestone Workers, Lung Function Indices, Spirometry

\section{Introduction}

In Ethiopia, Cobblestone work has become good job opportunity. However, workers are exposed to dust inhalation and physical injuries during excavating, cutting, drilling, handling, loading, transporting, chiseling and paving activities. Many studies show occupations involving stone materials increase chance of stone dusts exposure leading to proliferation and fibrotic alteration that change in spirometric lung function indices and cause respiratory problems [1,2]. Fine dust in underground and from stone could have metals and other substances that are risky for human health $[2,3]$. Such problems could result in changes in spirometric lung function indices (FVC, FEV1, FEV1/FVC, PEFR, PIFR and FEF25-75) that estimate lung volumes and lung capacities $[4,5]$.

Recording test trace is taken as a forced spirogram (volume over time) or as a flow-volume loop (flow against volume). Evaluation of forced expiration after a complete inhalation determine forced vital capacity (FVC) and forced expired volume during first second (FEV1). Ratio of FEV1/FVC, mean forced expiratory flow during middle half of FVC (FEF25-75\%), peak expiration flow rate (PEFR) and peak inhalation flow rate PIFR imply airways and lung problems [20]. Dozens of other indices (IRV, ERV, VT, FRC, VC, TLC, RV, FET etc) can be derived. Environmental and occupational risks closely associated with changes in these lung function indices resulting normal, obstructive, hyperinflation or restrictive lung function patterns $[5,6]$. Thus, dust particles affect transport and removal of air and deposited within respiratory system associated with change in lung volumes and lung capacities [7-9]. Previously, effect of stone dust and related dusts on pulmonary function of cobblestone workers was not studied. Therefore, the study was designed to determine changes in spirometric lung function indices of cobblestone workers.

\section{Materials and Methods}

The present study was conducted on cobblestone workers. Sampling population was chiseling and quarry workers. 
Comparative cross-sectional study was applied. Participants were within 18-35 years age range had working for one and above years and proportional non exposed groups were taken. Clearance from medical ethical committee and consent was obtained from participants. Exclusive and inclusive criteria were checked. Spiro metric lung function indices values and percent predicted mean values of lung functions (FVC, FEV1, FEV1/FVC, PEFR, PIFR and FEF25-75) were taken early morning and after a day stone dust exposure. A pocket sized digital spiro meter called Spiro pro made by
JEAGER was used to measure pulmonary function indices. Digital balance and measuring tape were used to measure weight and height so that BMI was calculated.

\section{Results}

In the course of the study, factors that affect lung function indices like mean \pm SD duration of years stayed at the cobblestone work, anthropometric measurements workers and control participants were considered.

Table 1. Anthropometric measurements in both exposed and controls groups.

\begin{tabular}{|c|c|c|c|c|}
\hline No. & Group & Age range (years) & Age years $($ Mean \pm SD) & $\operatorname{BMI}\left(\mathrm{kg} / \mathrm{m}^{2}\right)$ \\
\hline \multirow{3}{*}{1} & \multirow{3}{*}{ Controls } & $\mathrm{N}=151$ & $26.44 \pm 3.55$ & $21.38 \pm 2.62$ \\
\hline & & $18-26(n=88)$ & $23.90 \pm 1.73$ & $21.31 \pm 2.62$ \\
\hline & & $27-35(n=63)$ & $29.78 \pm 2.36$ & $21.47 \pm 2.64$ \\
\hline \multirow{9}{*}{2} & \multirow{3}{*}{ Exposed (Total) } & $\mathrm{N}=151$ & $26.52 \pm 4.12$ & $20.99 \pm 3.13$ \\
\hline & & $18-26(n=88)$ & $23.55 \pm 1.99$ & $21.13 \pm 3.31$ \\
\hline & & $27-35(n=67)$ & $30.52 \pm 2.55$ & $20.80 \pm 2.89$ \\
\hline & \multirow{3}{*}{ Quarry } & $(\mathrm{n}=73)$ & $27.59 \pm 3.98$ & $22.12 \pm 2.56$ \\
\hline & & $18-26(n=41)$ & $24.21 \pm 1.83$ & $22.19 \pm 2.65$ \\
\hline & & $27-35(n=32)$ & $30.79 \pm 2.20$ & $22.04 \pm 2.48$ \\
\hline & \multirow{3}{*}{ Chiseling } & $(\mathrm{n}=82)$ & $25.56 \pm 4.02$ & $19.98 \pm 3.26$ \\
\hline & & $18-26(n=47)$ & $23.20 \pm 2.01$ & $20.20 \pm 3.57$ \\
\hline & & $27-35(\mathrm{n}=35)$ & $29.93 \pm 2.89$ & $19.67 \pm 2.81$ \\
\hline
\end{tabular}

The study showed higher changes in spiro metric lung function indices. The mean values and percent predicted mean values of lung functions (FVC, FEV1, FEV1/FVC, PEFR, PIFR and FEF25-75) were significantly reduced $(\mathrm{p}<0.05)$.

Table 2. Paired t-test on lung function, predicted and actual value of workers and controls (Mean $\pm S D)$.

\begin{tabular}{|c|c|c|c|c|c|c|c|c|}
\hline \multirow{2}{*}{ Lungs Function Indices } & \multicolumn{4}{|c|}{ Control $(n=151)$} & \multicolumn{4}{|c|}{ Exposed $(n=155)$} \\
\hline & Predicted & Actual & t-value & p-value & Predicted & Actual & t-value & p-value \\
\hline FVC(L) & $4.985 \pm 0.425$ & $4.322 \pm 0.703$ & 12.228 & 0.000 & $4.869 \pm 0.755$ & $3.599 \pm 0.982$ & 15.390 & 0.000 \\
\hline FEV1(L/s) & $4.136 \pm 0.328$ & $4.267 \pm 0.701$ & -2.535 & 0.012 & $4.027 \pm 0.594$ & $3.524 \pm 0.850$ & 7.441 & 0.000 \\
\hline FEV $1 \%$ & $82.709 \pm 0.942$ & $98.940 \pm 3.412$ & -55.251 & 0.000 & $82.574 \pm 1.701$ & $98.652 \pm 5.45$ & -34.549 & 0.000 \\
\hline FEF25-75(L/s) & $4.343 \pm 0.303$ & $6.578 \pm 1.495$ & -19.373 & 0.000 & $4.222 \pm 0.537$ & $6.161 \pm 1.857$ & -13.589 & 0.000 \\
\hline PEFR(L/s) & $9.417 \pm 0.732$ & $8.748 \pm 2.204$ & 3.954 & 0.000 & $9.215 \pm 1.261$ & $8.632 \pm 2.470$ & 3.185 & 0.002 \\
\hline
\end{tabular}

Table 3. Lung function indices in cobblestone workers compared with controls.

\begin{tabular}{|c|c|c|c|c|c|c|c|c|c|}
\hline \multirow{2}{*}{$\begin{array}{l}\text { Lungs Function } \\
\text { indices }\end{array}$} & \multicolumn{2}{|l|}{ Actual } & \multicolumn{2}{|c|}{ Significance } & \multicolumn{2}{|c|}{ Percent predicted } & \multirow{2}{*}{$\begin{array}{l}\text { \%predicted } \\
\text { difference }\end{array}$} & \multicolumn{2}{|c|}{ Significance } \\
\hline & Control & Exposed & t-value & p-value & Control & Exposed & & t-value & p-value \\
\hline $\mathrm{FVC}(\mathrm{L})$ & $4.32 \pm 0.70$ & $3.53 \pm 0.99$ & -7.98 & $0.000 * *$ & $86.98 \pm 13.29$ & $74.65 \pm 19.39$ & 12.32 & -6.47 & $0.000 * *$ \\
\hline FEV1(L/s) & $4.26 \pm 0.70$ & $3.45 \pm 0.85$ & -9.03 & $0.000 * *$ & $103.596 \pm 15.88$ & $87.95 \pm 20.01$ & 15.64 & -7.56 & $0.000 * *$ \\
\hline FEV1\% & $98.9 \pm 3.41$ & $98.61 \pm 5.62$ & -0.61 & 0.540 & $119.636 \pm 4.410$ & $119.155 \pm 7.364$ & 0.48 & -0.69 & 0.490 \\
\hline FEF25-75(L/s) & $6.58 \pm 1.49$ & $6.00 \pm 1.71$ & -3.13 & $0.002 *$ & $150.464 \pm 32.60$ & $143.72 \pm 41.39$ & 6.74 & -1.58 & 0.11 \\
\hline PEFR(L/s & $8.75 \pm 2.20$ & $8.42 \pm 2.36$ & -1.24 & 0.22 & $92.92 \pm 22.17$ & $93.55 \pm 23.87$ & -0.63 & 0.24 & 0.81 \\
\hline
\end{tabular}

Values are mean $\pm \mathrm{SD} *$ significant $(\mathrm{p}<0.05) * *$ highly significant $(\mathrm{p}<0.001)$

**Significant difference existed in FVC, FEV1 and FEV1\% between controls and exposed groups $(\mathrm{p}<0.001)$. 
Table 4. Mean and standard deviation of lung functions measurement for both control and exposed group.

\begin{tabular}{|c|c|c|c|c|c|c|c|}
\hline \multirow{2}{*}{$\begin{array}{l}\text { Lung Function } \\
\text { Indices }\end{array}$} & \multirow{2}{*}{ Age range } & \multicolumn{2}{|c|}{ Control $(n=151)$} & \multicolumn{2}{|c|}{ Exposed (155) } & \multirow{2}{*}{ t-value } & \multirow[b]{2}{*}{ p-value } \\
\hline & & $\mathbf{N}$ & (Mean \pm SD) & $\mathbf{N}$ & (Mean \pm SD) & & \\
\hline \multirow{2}{*}{$\mathrm{VC}(\mathrm{L})$} & $18-26$ & 86 & $3.469 \pm 0.698$ & 89 & $3.280 \pm 0.921$ & 1.525 & 0.129 \\
\hline & $27-35$ & 65 & $3.509 \pm 0.601$ & 66 & $3.286 \pm 0.892$ & 1.681 & 0.095 \\
\hline \multirow{2}{*}{$\mathrm{FVC}(\mathrm{L})$} & $18-26$ & 86 & $4.3001 \pm 0.763$ & 89 & $3.686 \pm 1.034$ & 4.460 & $0.000 *$ \\
\hline & $27-35$ & 65 & $4.350 \pm 0.619$ & 66 & $3.487 \pm 0.897$ & 6.414 & $0.000 *$ \\
\hline \multirow{2}{*}{ FEV1(L) } & $18-26$ & 86 & $4.239 \pm 0.770$ & 89 & $3.574 \pm 0.828$ & 5.495 & $0.000^{*}$ \\
\hline & $27-35$ & 65 & $4.303 \pm 0.601$ & 66 & $3.462 \pm 0.875$ & 6.415 & $0.000 *$ \\
\hline \multirow{2}{*}{ FEV1\% } & $18-26$ & 86 & $103.157 \pm 14.674$ & 89 & $87.975 \pm 19.139$ & 5.833 & 0.000 \\
\hline & $27-35$ & 65 & $81.232 \pm 1.501$ & 66 & $103.508 \pm 18.27$ & -9.091 & 0.000 \\
\hline \multirow{2}{*}{ FEF25-75(L/s) } & $18-26$ & 86 & $6.499 \pm 1.633$ & 89 & $6.196 \pm 1.806$ & 1.164 & 0.246 \\
\hline & $27-35$ & 65 & $6.638 \pm 1.311$ & 66 & $6.108 \pm 1.923$ & 1.842 & 0.068 \\
\hline \multirow{2}{*}{ PEFR(L) } & $18-26$ & 86 & $8.610 \pm 2.305$ & 89 & $8.718 \pm 2.382$ & -0.305 & 0.760 \\
\hline & $27-35$ & 65 & $8.868 \pm 2.094$ & 66 & $8.490 \pm 2.587$ & 0.920 & 0.359 \\
\hline \multirow{2}{*}{$\operatorname{PIFR(L/s)}$} & $18-26$ & 86 & $5.180 \pm 2.368$ & 89 & $6.434 \pm 2.608$ & -3.323 & $0.001 *$ \\
\hline & $27-35$ & 65 & $5.401 \pm 2.198$ & 66 & $6.351 \pm 2.474$ & -2.330 & $0.021 *$ \\
\hline
\end{tabular}

Table 5. Exposure effect (\%) on spirometric parameters across gender and age groups.

\begin{tabular}{|c|c|c|c|c|c|c|c|c|c|}
\hline Age (yr) & Group & Gender & $\mathrm{VC}$ & FVC & FEV1 & FEV1\% & PEFR & FEF25-75 & PIFR \\
\hline \multirow{4}{*}{$18-26$} & \multirow{2}{*}{ Control } & Male $(n=74)$ & $3.50 \pm 0.65$ & $4.42 \pm 0.60$ & $4.37 \pm 0.61$ & $105.43 \pm 13.80$ & $8.95 \pm 2.17$ & $6.65 \pm 1.45$ & $11.39 \pm 52.45$ \\
\hline & & Female $(n=13)$ & $3.32 \pm 0.65$ & $3.91 \pm 0.60$ & $3.84 \pm 0.68$ & $93.77 \pm 12.01$ & $8.91 \pm 2.61$ & $6.11 \pm 1.68$ & $4.55 \pm 1.59$ \\
\hline & \multirow{2}{*}{ Exposed } & Male $(n=73)$ & $3.42 \pm 0.89$ & $3.80 \pm 1.03$ & $3.68 \pm 0.79$ & $87.08 \pm 18.73$ & $8.83 \pm 2.36$ & $6.21 \pm 1.86$ & $6.88 \pm 2.50$ \\
\hline & & Female $(n=10)$ & $2.29 \pm 0.64$ & $2.75 \pm 0.52$ & $2.73 \pm 0.49$ & $92.90 \pm 22.59$ & $6.94 \pm 1.14$ & $5.59 \pm 1.07$ & $3.94 \pm 1.73$ \\
\hline \multirow{3}{*}{$27-35$} & \multirow{2}{*}{ Control } & Male $(n=54)$ & $3.48 \pm 0.62$ & $4.34 \pm 0.76$ & $4.28 \pm 0.73$ & $104.47 \pm 18.46$ & $8.89 \pm 1.99$ & $6.81 \pm 1.47$ & $5.49 \pm 2.09$ \\
\hline & & Female $(n=10)$ & $53.30 \pm 0.77$ & $13.99 \pm 1.02$ & $0.443 .96 \pm 1.01$ & $98.40 \pm 17.24$ & $6.53 \pm 1.94$ & $5.49 \pm 1.26$ & $5.03 \pm 1.77$ \\
\hline & Exposed & Male $(n=51$ & $3.46 \pm 0.86$ & $3.66 \pm 0.89$ & $3.64 \pm 0.86$ & $89.29 \pm 21.53$ & $8.92 \pm 2.66$ & $6.38 \pm 1.96$ & $6.64 \pm 2.54$ \\
\hline
\end{tabular}

Values are mean \pm SD

Comparison of Similar Exposure Groups (SEGS): Mean $\pm \mathrm{SD}$ values of VC, FVC, FEV1 and FEF25-75 were lower in chiseling workers significantly $(p<0.05)$. PEFR reduction was very significant $(\mathrm{p}=0.000)$. FEV $1 \%$ and PIFR were lower but not significant. When we compare relative reduction between PEFR and PIFR, former one was significantly reduced $(\mathrm{p}=0.00)$ and reduction in PIFR was not significant (0.73).

Table 6. Comparison between subgroups (quarry and chiseling) of Cobblestone Workers.

\begin{tabular}{|c|c|c|c|c|}
\hline Lungs Function Indices & Quarry $(n=73 *)($ Mean \pm SD $)$ & Chiseling $(n=61 *)($ Mean \pm SD $)$ & t-value & p-value \\
\hline $\mathrm{VC}(\mathrm{L})$ & $3.604 \pm 0.791$ & $3.209 \pm 0.909$ & 2.700 & 0.008 \\
\hline FVC(L) & $3.912 \pm 1.008$ & $3.505 \pm 0.895$ & 2.425 & 0.017 \\
\hline FEV1(L) & $3.812 \pm 0.804$ & $3.443 \pm 0.824$ & 2.591 & 0.011 \\
\hline FEV $1 \%$ & $90.459 \pm 20.425$ & $84.262 \pm 19.333$ & 1.797 & 0.075 \\
\hline $\operatorname{PEFR}(\mathrm{L})$ & $9.618 \pm 2.435$ & $7.983 \pm 2.184$ & 4.013 & 0.000 \\
\hline FEF25-75(L) & $6.630 \pm 1.943$ & $5.908 \pm 1.701$ & 2.244 & 0.027 \\
\hline
\end{tabular}

All are males

\section{Discussion}

Normal lung function indices depend on gender, age and BMI. Race and geographical location may contribute to lung function indices variability. According to a study [10], Ethiopian men and women normal spirometric lung function test indices measured in Addis Ababa varied from results observed in other parts of the world. For example, mean FVC in men was 4.35 liters and 3.11 liters in women. The mean FEV1 was 3.52 liters for men and 2.45 liters in women.

The present study in cobblestone workers showed reduction in pulmonary function indices. Inhalation of dust over periods of time leads to proliferation of alveolar epithelium and fibrotic changes in lungs [11-13, 15]. Severity depends on several factors including chemical nature, physical state of inhaled substance, size, concentration of dust particles, duration of exposure and individual susceptibility. Proximity to sensitive receptors, prevailing wind direction, speed and nature of works topography influence level of impact [1].

The probable reason could be: chiseling workers were very proximate to dust and perform the chiseling without machinery support. Another could be body size. Quarry workers were a bit bigger in height and weight than chiseling workers although it was tried to match BMI $(22.12 \pm 2.56$ and $20.21 \pm 2.54$ ), respectively. This might be reflecting on lung function and justify discrepancy.

Pulmonary impairment in cobblestone workers and controls were interpreted to assess the severity of occurrence 
of obstructive and restrictive or mixed conditions. Pulmonary impairment conditions of the present study participants were analyzed combining the two ATS and ITS recommendations. Accordingly, About $4.6 \%$ and $18.1 \%$ of controls and exposed participants respectively have had obstructive condition respectively. About $2 \%$ of controls have had mixed pattern of lung function while $17.4 \%$ of exposed groups have had mixed condition. Neither control nor exposed group has had restrictive pattern alone. There was great lung function pattern difference between the groups. From the result, it could be stated that, the dust effect on lung function is on both airways and lungs.

Interpretation of PFTs is usually based on comparisons of data measured in an individual patient or subject with reference (predicted) values based on matched healthy subjects.

To say obstructive, restrictive, or normal pattern, the first step could be to evaluating FEV1/FVC ratio. If this ratio is less than the lower limit of normal $(=<70 \%)$, it shows FEV1 has fallen to a greater degree than FVC indicating presence of an obstructive defect. If this ratio is greater than lower limit of normal, then either the spirometry test is normal or a restrictive defect is present. The next step is to look at the FVC. If the FVC is less than predicted lower limit of normal $(=<70 \%)$, it verifies presence of restriction If FEV1\% become beyond $90 \%$ it is indicative for restrictive condition. If both FEV1/FVC ratio and percent predicted $\mathrm{FVC}$ values are within $70-90 \%$, this indicates normal condition [6, 20, 22].

A mixed ventilatory defect is characterized by coexistence of obstruction and restriction and is defined physiologically when both FEV1/FVC and FVC are below the $5^{\text {th }}$ percentiles of their relevant predicted values. Since FVC may be equally reduced in both obstruction and restriction, the presence of a restrictive component in an obstructed patient cannot be inferred from simple measurements of FEV1 and FVC. One can state that the FVC was also reduced, probably due to hyperinflation, but that a superimposed restriction of lung volumes cannot be ruled out. Conversely, when FEV1/VC is low and FVC is normal, a superimposed restriction of lung volumes can be ruled out [23].

\section{Conclusion}

From present study it could be concluded that dust emission during cobblestone work adversely affect pulmonary function. The mean values and percent predicted mean values of lung functions (FVC, FEV1, FEV1/FVC, PEFR and FEF25-75\%) were significantly reduced $(\mathrm{p}<$ 0.05). Reduction in pulmonary functions indices in chiseling workers was more significant compared to quarry workers.

\section{Recommendations}

Medical surveillance of early detection contributes to reduce burden of lung function impairments. Further studies should be conducted on many workers to make standing decisions and regulations. Concentration, composition, nature and specific effects of dust in the work site should be studied. Workers should be trained and appropriate PPEs should be provided. Guideline has to be developed to provide guidance on how to assess and reduce health impacts of dust emissions.

\section{Acknowledgement}

First of all, thanks to the Almighty God. My appreciation goes to Professor Yoseph Mengesha, Mr. Abayneh Elias and Mr. Aychew Adera for their help during data collection. Acknowledging my wife Fentaye Melaku is acknowledging me by any means; simply I love you my love! I acknowledge Addis Ababa University and Dire Dawa University for provision of fund for this study.

\section{References}

[1] TsunJen Cheng, Jing-Shiang Hwang. Effects of Concentrated Ambient Particles on Heart Rate and Blood Pressure in Pulmonary Hypertensive Rats. Environmental Health Perspectives. 2003.

[2] MattLoxham. Microscopic dust particles found in underground railways may pose health risk. Phys.org. University of Southampton.2013.

[3] Nwibo, Ugwuja, Nwambeke. Pulmonary Problems among Quarry Workers of Stone Crushing Industrial Site. IJOEM.2012; 3: 178-185.

[4] BarreiroT. TimothyJ. PerillowJ. An approach to interpreting spirometry. American academy of physicians. 2004 vol. 69:5

[5] Fauci's and Longo H. Principles of Internal Medicine. $17^{\text {th }}$ EditionMcGraw- Hill Companies, 2008.

[6] Feyrouz A. Interpreting pulmonary function tests: Recognize the pattern, and the diagnosis will follow. Cleveland Clinic Journal of Medicine. 2003; 70: 10.

[7] A guideline for managing the impacts of dust and associated contaminants from land development sites, contaminated sites remediation and other related activities. Department of Environment and Conservation. March, 2011.

[8] Praxsnih V. The Effects of Particulate Matter Air Pollution on Respiratory Health and on the Cardiovascular System. Jure Praznikar Prispelo 2011; 27:5.

[9] World health organization (WHO). Hazard Prevention and Control in the Work Environment: Airborne Dust, Dust Definitions and Concepts Available: WHO/SDE/OEH/1999/99.14

[10] Yoseph A Mengesha, Yalemtsehay Mekonnen. Spirometric Lung Function Tests in Normal Non Smoking Ethiopian Men and Women. Thorax 1985; 40: 465-468.

[11] Dino Pisaniello, Michael Tkaczuk and Sharyn Gaskin. Evaluation of Dust Inhalation Risk Factors A research study to reduce lung disease risks in SA quarries. Occupational \& Environmental Hygiene, Discipline of Public Health, School of Population Health, University of Adelaide. April 2013. 
[12] Mbbs Moeh Fracp. Respiratory problems, Occupational and environmental exposures. Websites: http://www.racgp.org.au/afp/Published,2012. Accessed on May 10, 2013.

[13] Shaikh K.. Sweeper's lung disease: a cross-sectional study of an overlooked illness among sweepers of Pakistan. International Journal of COPD. 2013; 8: 193-197.

[14] Smilee J. etal. Dust Exposure and Lung Function Impairment in Construction Workers. Journal of Physiol Biomed Sci.2011;24: 1: 9-13.

[15] Petr Brhel. Occupational Respiratory Diseases in the Czech Republic. Industrial Health.2003;41: 121-123.

[16] Canadian Centre for Occupational Health \& Safety. What are the Effects of Dust on the Lungs? Website: Last updated on October 1, 2012. Accessed on 30/5/13 10: 30 PM.

[17] Yoseph A. Mengesha and Asrat Bekele. Relative Chronic Effects of Different Occupational Dusts on Respiratory Indices and Health of Workers in Three Ethiopian Factories. American Journal of Industrial Medicine 1998:34: 373-380.

[18] Smilee J. et al. Acute Lung Function Response to Dust in
Street Sweepers. Journal of Clinical and Diagnostic Research. 2013 Oct, Vol-7 (10): 2126-2129.

[19] United States Department of Veterans Affairs. Sand, Dust and Particulates. Reviewed/Updated Date: June 3, 2013.

[20] Miller M. R etal. Standardization of spirometry, Eur. Respir. J. 2005; 26: 319-338.

[21] Dino P. et al. Evaluation of Dust Inhalation Risk Factors A research study to reduce lung disease risks in SA quarries. Occupational \& Environmental Hygiene, Discipline of Public Health, School of Population Health, University of Adelaide. April 2013.

[22] DavidL. etal. Grading the Severity of Obstruction in the Presence of a Restrictive Ventilatory Defect. CHEST 2002; 122: 4.

[23] Pellegrino R. et al Interpretative strategies for lung function tests. Eur Respir J 2005; 26: 5: 948-968.

[24] Mengesha Y. A. and Bekele A. Effect of acute exposure to different occupational dusts on pulmonary function indices of factory workers in Ethiopia. Afr newslett on occup health and safety $1997 ; 714-16$. 